\title{
TRABALHO DE PARCERIA ENTRE SUPERVISOR PEDAGÓGICO E PROFESSORES: POTENCIALIZAÇÃO DO PROCESSO DE ENSINO
}

\author{
Sulamita de Moura Lemes \\ Faculdade Cidade de Coromandel \\ sulamitagomes14@gmail.com \\ Tatiane Daby de Fátima Faria Borges \\ Faculdade Cidade de Coromandel \\ tatianedaby@gmail.com
}

Resumo: A escola atual necessita-se da interação entre o supervisor pedagógico e o professor, como forma de alcançar uma aprendizagem qualitativa, através da superação das dificuldades relacionadas à prática pedagógica por meio do trabalho de parceria entre ambos. O presente artigo realizado por meio de uma revisão da literatura teve como objetivo discutir a importância do trabalho de parceria entre o supervisor pedagógico e os professores para a efetivação do ensino. O estudo mostrou que muitos professores ainda consideram o supervisor pedagógico como um mero fiscalizador da prática docente, devido à origem da ideia de supervisão que surgiu no meio industrial e a característica de inspeção que esteve ligada a supervisão ao longo da história. Atualmente a atuação do supervisor está relacionada ao planejamento, reformulação do currículo, elaboração e execução do Projeto Político Pedagógico, ao acompanhamento do processo educativo, através da avaliação e as devidas recuperações, além da formação continuada dos docentes em serviço. Nesse contexto é fundamental a relação de parceria, realizada através do diálogo, reflexão e troca de experiências entre o supervisor pedagógico e os professores, que contribui para qualidade do processo ensino-aprendizagem, proporcionando um ensino eficaz, significativo e transformador.

\section{INTRODUÇÃO}

As transformações fazem parte do mundo contemporâneo, ocasionando avanços e modificações principalmente nos cenários tecnológicos e sociais, o que influencia consequentemente em alterações no contexto educacional.

Embora o cenário educacional tenha passado por diversas evoluções é possível ainda constatar a persistência de paradigmas tradicionais relacionados a supervisão. Segundo Lima (2005) isso deriva de sua origem no meio industrial e dos 
aspectos relacionados à inspeção, fiscalização e verificação do trabalho docente que a acompanharam ao longo da história o que acaba comprometendo o relacionamento entre o supervisor e o professor na contemporaneidade.

De acordo com Silva (2013) atualmente o professor é o principal responsável pelo desenvolvimento do discente no interior da instituição escolar. Porém a atuação do professor é baseada na ação do supervisor pedagógico, que é considerado o norteador da formação docente e parceiro na busca pela ressignificação da prática pedagógica.

Sendo assim o supervisor pedagógico deixou de ser controlador e fiscalizador, para promover a busca cooperativa à qualidade do processo ensino-aprendizagem, estimulando o trabalho em equipe, mediando a troca de experiências e orientando o estudo e trabalho docente.

No entanto, é possível notar que muitos professores ainda consideram o supervisor pedagógico um fiscalizador, controlador e investigador da atuação docente, definindo ações no interior da instituição de ensino.

Nesse sentido, há um afastamento entre o supervisor pedagógico e o professor, o que interfere na inter-relação entre ambos, atrapalhando as trocas de experiências que são primordiais na efetivação do processo de ensino de qualidade.

Diante dessa totalidade, esse estudo tem o intuito de propiciar aos leitores reflexões a respeito das relações estabelecidas no ambiente escolar, de modo específico os professores e supervisores pedagógicos, bem como enfatizar a importância do trabalho de parceria na busca pela qualidade do processo ensino-aprendizagem.

O presente estudo foi desenvolvido através da revisão da literatura. Para a concretização do mesmo foram consultados artigos científicos, monografia, dissertação e livros, obtidos por meio de acesso a bases de dados da internet, como sites de Instituições de Ensino Superior, bem como através de compras e empréstimos. Essas publicações vão desde obras clássicas a respeito do tema, até trabalhos atuais, publicados no idioma português. A procura de materiais teve como palavras-chave, prática supervisora, supervisor, professor, trabalho cooperativo e inter-relação. 
O objetivo da pesquisa será discutir a importância e as contribuições do trabalho de parceria entre o supervisor pedagógico e os professores para a efetivação do ensino.

\section{TRAJETÓRIA HISTÓRICA DA SUPERVISÃO}

De acordo com Nérici (1974) o termo supervisão surge a partir de dois vocábulos de origem latina, 'super', que significa superior e 'visão' que significa ver. Nesse sentido 'supervisão' significa ver sobre, o profissional que possui um ângulo de visão estratégico, onde é possível analisar o conjunto dos elementos, com a possibilidade de conduzir e aperfeiçoar o trabalho realizado por sua equipe.

Segundo Saviani (1999) era possível notar a presença da função supervisora desde as comunidades primitivas, quando as crianças eram educadas, estimuladas, protegidas e orientadas em suas ações pelos adultos.

Conforme Lima (2005), a ideia de supervisão teve inicio com o processo de industrialização norte-americana, no século XVIII e princípio do século XIX, em que os aspectos qualitativos e quantitativos eram concebidos por meio da repressão, checagem e monitoramento.

Para Alves e Duarte (2012) era possível observar a presença da função supervisora no 'plano de ensino' formulado pelo padre jesuíta Manoel de Nóbrega nas primeiras atividades educativas no Brasil que se iniciaram em 1549.

Almeida (1989) ressalta que em 1822 com a independência do Brasil, foi adotado o 'método do ensino mútuo' em todas as escolas de primeiras letras. Esse método era caracterizado pela instrução do professor aos alunos tidos como mais avançados e os mesmos orientavam os demais, enquanto o professor supervisionava o desenvolvimento da aula no geral. Nesse sentido o docente possuía funções de docência, bem como de supervisão.

Nérici (1974), afirma que a Primeira República (1889-1930) teve a inspeção escolar como principal característica, marcada pela fiscalização e pelo controle, característicos da supervisão industrial norte-americana. A inspeção escolar realizada através de visitas frequentes era responsável pelo cumprimento das regras de ensino, bem como pela integridade física das instalações das escolas, através da formalidade e rigidez, com a adoção de avaliações uniformes, que não levavam em consideração 
as necessidades e características das diversas regiões do país.

Segundo Geribello (1977) na Segunda República (1930-1945) nasceu a necessidade de adoção da assistência técnica, substituindo a fiscalização, com isso a supervisão assume o caráter de orientação pedagógica, em que o supervisor era visto como aquele que detinha todas as soluções para os problemas escolares.

Lima (2001) cita que na década de 1950 a população do país cresceu exorbitantemente, o que consequentemente fez aumentar o número de matrículas nas escolas, e a necessidade de um número relativo de professores, o que levou a ocupação de cargos de docência por pessoas sem formação específica. Contudo houve a necessidade de surgimento de cursos de atualização, como os realizados pelo Programa de Assistência Brasileiro-Americano ao Ensino Elementar (PABAEE), destinado a capacitação, treinamento e aperfeiçoamento dos professores do ensino primário, de acordo com o modelo de educação americana.

Araújo (1967) destaca que posteriormente o PABAEE criou os departamentos assistidos por técnicos americanos de Supervisão e Currículo, para a formação de supervisores com a finalidade de desenvolver lideranças no interior do sistema educacional brasileiro para reprodução das analogias capitalistas, para o máximo de professores possível.

Para Urbanetz e Silva (2008), a Lei n. ${ }^{\circ} 5540$ de 1968 foi muito importante para a supervisão, pois ampliou o campo de atuação dos supervisores para todo o ensino de $1^{\circ}$ e $2^{\circ}$ graus. Além de criar novas habilitações no curso de Pedagogia, como planejamento, administração, inspeção, supervisão e orientação. Entretanto, por conta do período ditatorial o trabalho dos supervisores voltava-se exclusivamente para a fiscalização da prática educativa dos professores. Bem como é ressaltada a relevância da Lei Federal $n^{\circ} .5692$ do ano de 1971, que formulou as Diretrizes e Bases para o ensino de $1^{\circ}$ e $2^{\circ}$ graus, pois regularizou de forma definitiva o serviço de supervisão educacional.

Santos (2012) afirma que na década de 1980 a população começou a se conscientizar sobre os problemas sociais existentes e da precariedade na qual se encontrava a educação brasileira. Entretanto a culpa pelo fracasso escolar recaiu-se sobre o profissional supervisor, sobre a justificativa de que o mesmo não estava trabalhando ao lado do docente na busca de soluções para os problemas 
educacionais da época, além de priorizar a prática individualizada, o que provocou uma descaracterização dos serviços de supervisão, a denominada fase de 'negação dos especialistas'.

Ainda de acordo com o autor supracitado, a década de 1990 foi marcada pela Lei $n^{\circ} .9394$ de 1996, a Lei de Diretrizes e Bases da Educação Nacional, que permite aos sistemas educacionais estabelecerem sua estrutura curricular própria, sobre articulação do supervisor, de acordo com sua realidade e necessidades. Nesse contexto é priorizada a garantia da qualidade do processo ensino-aprendizagem, através do trabalho contextualizado e cooperativo.

\section{A ATUAÇÃO DO SUPERVISOR PEDAGÓGICO NO AMBIENTE ESCOLAR}

Conforme Alonso (2003), o trabalho do supervisor pedagógico não se limita a assistência técnico-pedagógica, sua atuação é planejada em torno de objetivos explícitos, ocupando um papel de responsabilidade e liderança frente ao processo educativo em direção ao plano de trabalho da instituição.

Müller (2011) destaca que a liderança exercitada pelo supervisor pedagógico não possui sentido de hierárquica, marcada pela superioridade e delegação de ordens como antes, essa nova liderança é democrática, através da cooperação na busca pelo alcance dos objetivos formados pela escola, de responsabilidade de toda a equipe escolar.

Segundo Rangel (2002) na construção democrática do PPP o supervisor possui a função de articulador, norteando a participação de todos os membros da escola, levando-os a refletir sobre a realidade, as necessidade e características da comunidade em que a instituição está concentrada, ressaltando a importância da participação de cada integrante da equipe escolar tanto para o planejamento das propostas e metas, como para a execução das mesmas.

Rangel (2007) cita que na construção do planejamento o supervisor pedagógico deve levar os professores a refletirem sobre o público no qual eles irão trabalhar, além de orientar os docentes em direção aos objetivos estabelecidos, aos conteúdos que deverão ser trabalhados, a escolha das metodologias e materiais que serão utilizados e a adoção de formas apropriadas de avaliação. O supervisor também deve ressaltar aos professores sobre a flexibilidade que o planejamento possui e a importância da 
reflexão-ação-reflexão durante todo o processo.

Nérici (1978) menciona que intimamente ligada ao planejamento está a reformulação do currículo. Nessa etapa o supervisor pedagógico deve oferecer subsídio aos professores para que eles reflitam sobre as peculiaridades da escola e da comunidade, com o intuito de proporcionar uma aprendizagem significativa, aliada a uma prática contextualizada e interdisciplinar.

Rangel (2007) afirma que posteriormente o supervisor pedagógico acompanha tudo o que foi planejado no PPP e nos planos de ensino, por meio de contínuas observações e análises. Nesse processo o supervisor identifica as adversidades apresentados e em conjunto com os professores realizam o replanejamento das ações pedagógicas.

De acordo com Rangel (2002) a função de avaliação desenvolvida pelo supervisor pedagógico leva em consideração o processo e não apenas o resultado final, através das observações e análises dos progressos e mudanças de comportamentos dos alunos e também dos professores.

Para Dias (2005) consequentemente o supervisor, busca intervenções em parceria com sua equipe pedagógica para os problemas identificados no processo de avaliação, com a intenção de superar as dificuldades encontradas, tanto dos alunos como dos professores, com o intuito de tornar o processo de ensino-aprendizagem mais significativo.

Santos (2012) ressalta que também faz parte das atribuições do supervisor pedagógico o direcionamento e a valorização da formação continuada dos professores em serviço, através de estudos e pesquisas, reflexão sobre a prática pedagógica, o diálogo acerca de temas emergentes, além da troca de experiências entre toda a equipe. Essas ações auxiliam os docentes a acompanhar os processos de transformações, que estão em ritmos cada vez mais acelerados e que necessitam ser acompanhados pelo contexto educacional.

\section{CONTRIBUIÇÕES DO TRABALHO DE PARCERIA ENTRE O SUPERVISOR PEDAGÓGICO E OS PROFESSORES}

Carlos e Lodi (2012) afirmam que a supervisão pedagógica praticada atualmente é a democrática, que tem como base o respeito mútuo e o diálogo, no 
processo de tomada de decisões e no desenvolvimento do trabalho em equipe, no qual todos os membros da escola são tidos como responsáveis pela qualidade do processo educativo.

Conforme Dias (2005) o alcance dos objetivos estabelecidos somente se torna possível com o trabalho em equipe. Entretanto esses objetivos necessitam partir das necessidades cotidianas e anseios de cada integrante da equipe. Quando isso acontece os objetivos a serem alcançados são considerados um desejo de conquista, e não uma obrigação.

Almeida e Placco (2001) ressaltam que as observações cotidianas realizadas pelo supervisor pedagógico constituem uma oportunidade de admirar os saberes e identificar os problemas, oportunizando a projeção de soluções para os mesmos.

De acordo com Müller (2011) o supervisor pedagógico precisa ter disposição para ouvir, pois ouvindo os professores ele irá compreender de forma mais ativa os anseios e as angustias dos docentes, tendo oportunidade de diagnosticar suas necessidades e buscar soluções eficazes.

Ainda segundo Müller (2011) o diálogo é tido como o alicerce dos relacionamentos interpessoais no ambiente escolar, entretanto o professor precisa sentir segurança e tranquilidade ao falar com o supervisor pedagógico, para que as trocas de experiências, saberes e ideias aconteçam de forma plena.

Conforme Martinazzo (2005), as equipes são geralmente heterogêneas, constituídas por pessoas com opiniões distintas, porém essas opiniões não precisam ser aceitas e sim respeitadas. Mas nada impede que essas opiniões sejam debatidas através de críticas construtivas, induzindo essas pessoas a refletirem sobre sua postura e sua forma de pensar e agir.

Fernandes (1997) afirma que o supervisor pedagógico não detém todo o conhecimento didático-pedagógico, para consulta dos professores. A tarefa dele é leva os docentes a refletirem sobre sua atuação, proporcionado o auto-entendimento e a conquista da autonomia para pensar e repensar sua prática pedagógica.

Dias (2005) menciona que devido às diversas transformações do mundo contemporâneo o contexto educacional necessita ser questionado, refletido e reformulado constantemente pelos docentes, ações estas estimuladas e subsidiadas pelo supervisor pedagógico, com a finalidade de acompanhar as inovações da 
sociedade, proporcionando assim uma aprendizagem significativa aos alunos.

Para Alarcão (2007) o processo de reflexão precisa acontecer em equipe e não de forma isolada, o supervisor pedagógico nesse sentido deve auxiliar e valorizar a troca de experiências entre toda a equipe pedagógica, para que a instituição se torne uma escola crítica-reflexiva, tendo a reflexão e o trabalho coletivo como o caminho para o alcance da aprendizagem qualitativa.

\section{CONSIDERAÇÕES FINAIS}

Considerando o estudo realizado foi possível constatar que a centralização e burocratização que fizeram parte da trajetória histórica da supervisão fizeram com que a real atuação do supervisor pedagógico posteriormente não fosse reconhecida pelos demais profissionais da educação básica.

Nesse sentido, é necessária a conscientização dos professores a respeito da superação da fase controladora que esteve ligada ao supervisor ao longo do tempo, sendo fundamental ressaltar as contribuições do trabalho cooperativo dentro das intuições de ensino.

Atualmente o supervisor é um profissional chave no processo educativo, pois busca uma nova escola e novos docentes, para a formação de novos alunos, adaptados as transformações e necessidades da sociedade contemporânea. Sendo as atribuições e a prática supervisora direcionadas no sentido do trabalho coletivo junto aos professores, em prol do processo do ensino-aprendizagem de qualidade.

\section{REFERÊNCIAS}

ALARCÃO, I. Professores reflexivos em uma escola reflexiva. 5. ed. São Paulo: Cortez, 2007.

ALMEIDA, J. R. História da instrução pública no Brasil (1500 - 1889). Brasília/ São Paulo: INEP/ PUC - SP, 1989.

ALMEIDA, L. R.; PLACCO, V. M. N. S. (orgs.) O coordenador pedagógico e o espaço para mudança. São Paulo: Loyola, 2001.

ALONSO, M. A supervisão e o desenvolvimento profissional do professor. In:FERREIRA, N. S. C. (org.). Supervisão educacional para uma escola de qualidade. 4. ed. São Paulo: Cortez, 2003. p. 167-182.

ALVES, A. M. L. S.; DUARTE, E. A. F. G. Supervisão escolar: missão, exercício, desafios e perspectivas. Pergaminho, Patos de Minas, n. 3, p. 1-22, nov. 2012. Disponível em: 
$<$ http://pergaminho.unipam.edu.br/documents/43440/43870/supervisor-escolar.pdf>. Acesso em: 17 out. 2016.

ARAÚJO, M. Y. A. Experiência de linguagem oral na escola primária. 7. ed. Rio de Janeiro: Editora Nacional de Direito, 1967.

CARLOS, J. A.; LODI, I. G. A prática pedagógica em supervisão escolar: a importância da inter-relação entre o supervisor pedagógico e o corpo docente. Evidência, Araxá, v. 8, n. 8, p. 55-66, 2012. Disponível em: $<$ https://www.google.com.br/webhp?sourceid=chromeinstant\&ion=1\&espv=2\&ie=UTF-

8\#q=a\%20pratica $\% 20$ pewdagogfica $\% 20$ em $\% 20$ supervisao $\% 20$ escolar $>$. Acesso em: 22 ago. 2016.

DIAS, E. S. A participação do supervisor escolar frente à gestão democrática para uma educação de qualidade: desafios atuais. 2005.72 f. Monografia (Especialização e Gestão Educacional) - Universidade Federal de Santa Maria UFSM, Santa Maria, 2005. Disponível em:

$<$ http://repositorio.ufsm.br:8080/xmlui/bitstream/handle/1/1522/Dias Ediomara da Silva.pdf? sequence=1\&isAllowed=y. >. Acesso em: 10 jan. 2017.

FERNANDES, M. M. A opção da supervisão diante da ambivalência. In: JÙNIOR C. A. S.; RANGEL, M. (orgs). Nove olhares sobre a supervisão. Campinas: Papirus, 1997. p. 111122.

GERIBELLO, V. P. Anísio Teixeira: analise e sistematização de sua obra. São Paulo: Atlas, 1977.

LIMA, E. C. Um olhar histórico sobre a supervisão. In: RANGEL, M. (org). Supervisão pedagógica: princípios e práticas. Campinas: Papirus, 2001. p. 69-78.

LIMA, E. C. Um olhar histórico sobre a supervisão. In: RANGEL, M. (org.). Supervisão pedagógica: princípios e práticas. 5. ed. Campinas: Papirus, 2005. p. 69-80.

MARTINAZZO, C. J. Pedagogia do entendimento intersubjetivo: razões e perspectivas para uma racionalidade comunicativa na Pedagogia. ljuí: Unijuí, 2005.

MÜLLER, C. M. A práxis supervisora educacional: do controladorismo à coordenação. 2011.99 f. Dissertação (Mestrado em Educação nas Ciências) - Universidade Regional do Noroeste do Estado do Rio Grande do Sul, ljuí, 2011. Disponível em: <http://bibliodigital.unijui.edu.br:8080/xmlui/bitstream/handle/123456789/576/Disserta\%C3\% A7\%C3\%A3o-\%20Camila\%20Mariane \%20M\%C3\%BCller.pdf? sequence=1>. Acesso em: 16 ago. 2016.

NÉRICI, I. G. Introdução à supervisão escolar. 2. ed. São Paulo: Atlas, 1974.

NÉRICI, I. G. Introdução à supervisão escolar. 4. ed. São Paulo: Atlas, 1978.

RANGEL, M. Supervisão: do sonho à ação - uma prática em transformação. In:FERREIRA, N. S. C. (org.). Supervisão educacional para uma escola de qualidade: da formação à ação. 3. ed. São Paulo: Cortês, 2002. p. 69-96. 
RANGEL, M. Supervisão: do sonho à ação - uma prática em transformação. In: FERREIRA, N. S. C. (org.). Supervisão Educacional para uma escola de qualidade: da formação à ação. 6. ed.São Paulo: Cortez, 2007.p. 69-96.

SANTOS, M. P. História da supervisão educacional no Brasil: reflexões sobre política, pedagogia e docência. Rio de Janeiro: Wak, 2012.

SAVIANI, D. A supervisão educacional em perspectiva histórica: da função à profissão pela mediação da idéia. In: FERREIRA, N. S. C.(org.). Supervisão Educacional para uma escola de qualidade: da formação a ação. São Paulo: Cortez, 1999.p. 13-38.

SILVA, G. T. Supervisor pedagógico: formador ou fiscalizador. Revista de educação, ciências e cultura, Canoas, v. 18, n. 2, p. 55-68, jul.I dez. 2013. Disponível em: $<$ http://www.revistas.unilasalle.edu.br/index.php/Educacao/article/viewFile/1278/1020>. Acesso em: 13 fev. 2017.

URBANETZ, S. T.; SILVA, S. Z. Orientação e supervisão escolar. Curitiba: IBPEX, 2008. 